\title{
Introduce XBRL To Business Students
}

Sheree M. Corkern, PhD, CPA, Mississippi College, USA

Mark I. Morgan, PhD, CPA, CFE, Mississippi College, USA

\begin{abstract}
This paper informs business instructors and educators about XBRL (Extensible Business Reporting Language) so that they can introduce it to their students and expand their students' understanding of how it relates to the accounting profession. Even though the financial community has entered a new age with this standardized reporting language, many business educators and even accountants old and new to the profession are not informed about XBRL nor have an idea of its potential benefits. With this paper, educators and students can learn the definition of XBRL, its history, and its current uses. The information educates the reader about the evolution of XBRL over the past two decades as well as its benefits so readers can become aware of the value of this now-worldwide application. The paper includes the SEC and FDIC adoption of this computer language as an international standard that aims to improve the speed, accuracy, and transparency of business reporting.
\end{abstract}

Keywords: Business Education; Financial Reporting; Business Reporting Language; XBRL; XML

\section{INTRODUCTION}

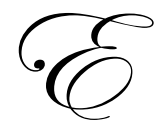

xtensible Business Reporting Language (XBRL) is a digital business reporting language that facilitates the transfer, sharing, and reuse of business financial information. The goal is to improve the speed, accuracy, and transparency of business reporting between operating segments within companies and when exchanging information outside of the company, whether to vendors or in compliance with regulatory agencies. The potential for change XBRL could make to reporting may very well be similar to what Universal Product Codes (UPC) did to retail product packaging. The introduction, history, benefits, and current status of XBRL will help students value this worldwide phenomenon. The Securities and Exchange Commission (SEC) and the Federal Deposit Insurance Corporation (FDIC) have played a role in the adoption of what is sure to become a new international standard. Readers are encouraged and challenged to experience XBRL by visiting the website http://www.tryxbrl.com for a hands-on application of this new language.

\section{DEFINITION}

XBRL acts as a universal translator by providing an emerging standardized electronic coding language that simplifies the process of business reporting. Often thought of as an accounting standard but not officially promulgated, this coding language is a standards-based open universal method that tags data to make it machinereadable. XBRL is open in the sense that the electronic readable codes that act as standard definitions are available to all, and access is universally adoptable. The coding is designed to automate and simplify the exchange of financial data by applying XML tags, referred to sometimes as XML technology. The tags identify the individual activity of each piece of data associated with business financials and interprets them the same from financial reporting anywhere.

More specifically, XBRL uses these computer tags to give a standard definition for each line item on a financial statement. These tags may be developed for not only a line item type of account (i.e. assets, liabilities, equity, revenue and expenses) associated with the major financial statements, but also for disclosure notes or for comprehensive income reporting requirements. They may be likened to bar codes used to label information instead of products. However, they are more than simple identifiers of information; they are electronic readable embedded codes that provide a range of descriptive and authoritative information about each term, element or concept that may be in financial reports. Just as bar codes are used to make it easier to manage inventory and sales, XBRL language 
makes it easy and consistent to prepare, publish, exchange, and analyze the financial information of companies. Each item tagged in a financial report tells standard software what the item represents and how it relates to other items. The content within each line item remains the same, but the data becomes much easier to import and export to a diverse set of information consumers, thus enhancing communication along the business supply chain. ${ }^{1}$

The standardization of these tags is making financials more readable and understandable for all developing software applications. The XBRL format eliminates the need for transcribing data from one application to another because the data is independent of the computer application with which it was created. This brings consistency of recognition, of categorization and of classification to each financial item and helps to accommodate existing accounting standards electronically. Broad use of XBRL could allow users to analyze and compare hundreds of companies anywhere in the world in an instant. Predictably, XBRL can influence the global accounting profession by creating a very structured and rational approach to the setting of accounting standards that ultimately must be understood by computer software universally.

Once the financial information is in the XBRL format, the information can be sorted and rendered into different forms such as an annual report, a tax return, or an SEC filing. Recognizing each individual item in such detail enables its identification. This offers another incentive for standardization because the items must be consistently identified regardless of national and international discord in reporting standards, differing languages, or contradicting accounting and auditing terminology. The tagged line item includes a considerable amount of contextual information. Examples of information included in the tagged item may be the company name, the accounting period, the currency type, or the account type. These XBRL tags are included in a dictionary providing a standard definition, which is commonly called taxonomy. Formatting the financial data with XBRL tags has the potential to cancel the indecision associated with determining whether an item reported by Company $\mathrm{A}$ is the same as that same item reported by Company B.

More specifically, taxonomies are standardized lists of accounting terms, relationships, and business rules that are used to identify and locate each item in the financial statements. At present each country already has or is in the process of developing a taxonomy to reflect its own accounting rules and regulations, and the International Accounting Standards Board is developing the international taxonomy. Taxonomies of this kind are often compared with a standard chart of accounts for the accounting profession but are much more extensive. They are vast libraries of line tags used to map a harmonized internal chart of accounts to common terms used externally.

The first published taxonomy for financial reporting of commercial and industrial companies under U.S. Generally Accepted Accounting Principles (GAAP) was released July 31, 2000. Today there are approximately 13,000 GAAP-approved terms for use in tagging financial data in the U.S. Once the XBRL tags are mapped for a particular company's financial statements, the template can be reused for subsequent filings. These templates do away with the need for time-consuming interpretations and conversions because the company only has to tag its data once. XBRL is also extensible, allowing it to be customized for a unique industry. For example, if a company has data to communicate that does not meet an established XBRL taxonomy definition; the company may create a custom tag for that data item.

\section{STANDARDIZATION OF EXCHANGING DATA}

The accounting profession has used different mechanisms for exchanging data throughout its history. The accession of the computer and then evolution of information technology has continued to change the way accountants exchange and present financial information, a process commonly referred to as business reporting. The result has been the development of a mix of software solutions with electronic spreadsheets and word processing programs used routinely and traditionally now to produce financial reports. As the global economy has expanded, the demand for the manipulation and transference of financial data has become more intense. This pressure compelled the production of differing types of software and systems that could batch and sort data more easily and quickly. Often the differing sources of information would require multiple learning curves for personnel and

\footnotetext{
${ }^{1}$ Farewell, Stephanie M. (Spring 2006). An Introduction to XBRL Through the Use of Research and Technical Assignments. Volume 20 (1).
} 
cumbersome rekeying of data between systems in order to analyze and/or review financial reports. Adding to this frustration was the perceived ease of movement of information over the internet that intensified the requirement that data be sent to regulatory agencies in various formats. Companies' reports were often made in American Standard Code for Information Interchange (ASCII) or HyperText Markup Language (HTML) format. These formats had been designed to enhance reading with human eyes, but they are not as computer readable and discernible as XBRL. The industry needed a standardization of data production that would augment exchange and dissemination more efficiently and avoid duplication of efforts. Few have shown as much promise as the emergence of XBRL.

Charles Hoffman, CPA, developed a new idea for the distribution and exchange of business and financial information using an eXtensible Markup Language (XML) for financial reporting. In 1998 he presented a prototype to the American Institute of Certified Public Accountants (AICPA). The AICPA saw the potential of XML-based financial statements if adopted as a global standard and agreed to fund the effort to develop the idea further. Shortly thereafter, a steering committee was formed, and at its first meeting in October 1999, development began on the first XBRL taxonomy. XBRL was derived from the XML standard format. A taxonomy is a technique of classification into ordered categories those like and similar financial accounting statement components. The committee then held the first press conference in April 2000 to introduce the new brand: XBRL. The steering committee then released the first guidance named XBRL Specification 1.0 for financial statements for the commercial and industrial sectors in the United States the following July and announced the formation of an international organization for global expansion and adoption of XBRL. In February of the next year, 2001, representatives from 10 countries attended the first XBRL international conference. International representatives met again in June and October with increasing participation and stronger attendance. In the October conference, XBRL jurisdictions were formed in an attempt to support neighbor development of XBRL in many countries and regions. ${ }^{2}$

A flurry of XBRL initiatives began as a result of the marked interest and potential uses seen in XBRL. A consortium of governmental and corporate entities took notice and committed time and effort. In December 2001, this new computer reporting language was tested by the banking industry in the United States with Bank of America successfully piloting XBRL using real client information. In Australia in February 2002, the Prudential Regulatory Agency was the first bank regulator to overhaul data collection from 11,000 super funds, insurers and banks regularly required to report. In March 2002 technology giant Microsoft was the first company to report its financials in XBRL.

The U.S. SEC established a voluntary program in 2005 for using XBRL to report financial information on their document collection system, Electronic Data Gathering Analysis and Retrieval (EDGAR). The three years that followed encouraged voluntary XBRL submissions. Mandatory requirements for using XBRL to report financial information to EDGAR began phasing in June 2009 and now, as of filing periods ending on or after June 15, 2011, all public companies are required to submit financial statement documents in XBRL format to the SEC.

\section{BENEFITS}

XBRL offers benefits to companies, investors, analysts, financial institutions, regulators, and all users of business information by greatly increasing the effectiveness and efficiency of the recording and transferring of financial data. The XBRL format reduces the chance of error within the data and allows easier exchange of data, which ultimately will improve the transparency of financial information. Users will have the ability to access financial information more quickly and will not have to linger over a lengthy financial report to find specific types of information. XBRL facilitates the reuse of information and reduces the need for redundant data entry. Also, and most importantly, the format gives more users the power to access and analyze a particular company's performance and then contrast it to similar companies.

Financial information is now constantly bundled and reused for multiple purposes, both within the company and externally. XBRL provides information in a configuration that can satisfy all of the reporting requirements, eliminating the repetitive processes of rekeying and transferring the data to all destinations. XBRL can act as an automated extension of the company's accounting system without manual or repetitive effort and create a seamless transfer of business information.

\footnotetext{
${ }^{2}$ http://www.xbrl.org.history-print.aspx 
XBRL also makes financial statements more searchable and comparable, thus making the indexing and searching of lengthy documents significantly easier. XBRL results in a seamless transfer of data between software packages without the need for costly interfaces and an easy transfer of data outside the organization. Traditionally, when financial numerals were reported to various internal and external users, such as the Internal Revenue Service, the SEC, the FDIC, as well as financial analysts, the recipients had to transfer each digit into their own specific analytical program. XBRL results in more time analyzing and using financial information and less time physically and manually processing data.

\section{CONCLUSION}

With the trend toward using more interactive data, XBRL is becoming ever more vital to the practice of accounting, both domestically and internationally, because it greatly improves access to and analysis of reported data. Because companies need to share information with one another in addition to sharing it with regulatory authorities, they are turning to XBRL to simplify and streamline this process. This increased demand has prompted the rise of third-party services that handle the entire process or offer software that applies the XBRL tags as part of an automated process. As a result, using XBRL is easier than ever.

Currently, XBRL International is composed of approximately 28 local jurisdictions including the United States, Australia, China, Germany, France, Japan, Spain, South Korea, Canada, and the United Kingdom. These local jurisdictions foster and contribute to the international development of XBRL. The implications of XBRL are far reaching, in that the computer language has the potential to someday aid in the effort to identify, access, and end the flow of money to terrorist networks. Financial institutions have always filed reports with the FBI to identify unusual transfers of funds and possible money laundering in paper. XBRL gives the FBI and other law enforcement the opportunity to offer a seamless and easy transfer of data between agencies and organizations. The retrieval and analysis process for them could become much more competent and less time-consuming by allowing them to respond more rapidly.

The SEC initiated a voluntary reporting program using XBRL starting in 2005. The agency has now posted final rules mandating XBRL for public companies over a three-year phase-in period. The first phase included all U.S. and foreign large accelerated filers that file in U.S. GAAP and have a public float of five billion or greater. These companies were required to provide XBRL financials, beginning with fiscal periods ending on or after June 15, 2009. The second phase included all other large accelerated filers reporting in U.S. GAAP, and these were required to comply with the mandate approximately a year later. The third and ongoing phase includes the remaining companies who file in U.S. GAAP and all foreign private issuers who file in International Financial Reporting Standards (IFRS). Additionally, each filer is required to post the XBRL documents on its Web site. The FDIC also requires companies to add XBRL tags to their financial filings, and more regulatory agencies are adopting this requirement. Congress has even begun introducing bills calling for the use of XBRL.

As more countries require XBRL as part of their regulations, they are also streamlining the submission process for companies. Instead of submitting multiple paper forms, companies can now submit a single XBRL document to the database. The relevant authorities can then access the information that they need from that database with a much smaller workforce than would be required to receive and process multiple paper forms. Ultimately XBRL will affect all companies that produce business reports to be used by different organizations.

\section{AUTHOR INFORMATION}

Sheree M. Corkern is an Assistant Professor of Accounting at Mississippi College University. Her research interests involve pedagogical issues and the practical issues that surround the accounting industry. She teaches courses in intermediate accounting, principles of accounting, and accounting information systems. Mailing address: is Mississippi College, School of Business, P.O. Box 4014, Clinton, MS 39058. E-mail: corkern@mc.edu

Mark I. Morgan is an Assistant Professor of Accounting at Mississippi College. His research interests include teaching methods for adult students, current trends in the accounting profession, and issues related to the study of fraud examination. He teaches auditing, graduate auditing, issues in accounting decision-making, fraud examination, 
and CPA review. Formerly a criminal investigator, he has considerable legal experience prosecuting fraudulent financial cases. Mailing address is Mississippi College, School of Business, P.O. Box 4014, Clinton, MS 39058. E-mail: morgan00@mc.edu. Corresponding author.

\section{REFERENCES}

1. American Institute of Certified Public Accountants. (2011). XBRL Update. Observations and Recommendations for XBRL Implementations for SEC Reporting in the U.S. Issued by the AICPA XBRL Assurance Task Force. Available on-line at: http://www.aicpa.org/interestareas/frc/accountingfinancialreporting/xbrl/downloadabledocuments/xbrl\%20 update final.pdf

2. Bagranoff, N. A., Simkin, M. G., \& Norman, C. S. (2005) Core Concepts of Accounting Information Systems. Hoboken, N.J.: John Wiley \& Sons.

3. Baldwin, A. A., Brown, C.E., \& Trinkle, B.S. (2006). XBRL: An Impacts Framework and Research Challenge. Journal of Emerging Technologies in Accounting, 3, 97-116.

4. Farewell, S. M. (2006). An Introduction to XBRL through the Use of Research and Technical Assignments. Journal of Information Systems: 20, 161-185.

5. Financial Accounting Foundation. 2011.2011 U.S. GAAP Financial Reporting Taxonomy Adopted and Supported by SEC Effective February 28, 2011. Available on-line at: http://www.accountingfoundation.org/cs/ContentServer?c=FAFContent_C\&pagename=Foundation/FAFCo ntent_C/FAFNewsPage\&cid=1176158284334

6. Hall, J. A. (2011). Accounting information systems. Mason, OH: Cengage Learning.

7. Holt, O. (2007) Is XBRL the Answer To The Accountant's Red Tape Burden? Accountancy Ireland, 39, $38-41$.

8. Kull, J.L., Miller, L. E., Clair, J. A. \& Savage, M. (2007). Interactive Data - XBRL: A Revolutionary Idea. Journal of Government Financial Management, 10-14.

9. $\quad$ US Securities and Exchange Commission. 2011. Interactive Data to Improve Financial Reporting. Accessed December 7, 2011. Available on-line at: http://www.sec.gov/rules/final/2009/33-9002.pdf

10. XBRL.org. available at: http://www.xbrl.org/ 
NOTES 